\title{
Early disease management strategies in case of a smallpox outbreak
}

\author{
Andrea Ammon ${ }^{1}$, Julia Sasse ${ }^{2}$ and Klaus Riedmann ${ }^{2}$ \\ ${ }^{1}$ European Center for Disease Prevention and Control (ECDC), 17183 Stockholm, Sweden; \\ ${ }^{2}$ Robert Koch-Institut, Seestrasse 10, 13353 Berlin, Germany
}

\begin{abstract}
As a consequence of the threat of smallpox being potentially used as a means of bioterrorism, many countries have developed preparedness plans for smallpox in the past few years. This chapter summarizes some of the most important issues for the management of smallpox. Usually, the strategy for the management of clinical cases of poxviruses includes the early detection of cases, rapid laboratory diagnosis, an assessment of the risk of further spread and containment measures. For the early detection, different systems are being tested to identify suspected cases before a diagnosis is confirmed (e.g., syndromic surveillance). Also it is necessary to provide special training on the disease pattern, including differential diagnosis, to clinicians and practitioners. If a suspected case has been identified, rapid diagnostic tests are required. In addition to the national and international notifications based on given case definitions, certain measures are necessary to allow an initial risk assessment of the epidemic development. For a rapid risk assessment, the investigations should follow the algorithms of epidemiological outbreak investigation such as the tracing and identification of exposed contacts and the sources of infection. Further decisions have to be taken on the basis of a continuous risk assessment. Countermeasures can be divided into medical and non-medical ones. The choice of an adequate vaccination strategy as a medical countermeasure for the case of a re-emergence of smallpox very much depends on the epidemic scenario, and the general availability and quality of a vaccine. Logistic aspects of the vaccination strategies have to be considered in preparedness planning (e.g., resources necessary for the implementation of mass vaccinations), and also the prioritization of groups to be vaccinated. In addition non-medical measures to prevent the spread of infection, such as the isolation of cases and quarantining of exposed persons (e.g., contact persons of confirmed cases) have to be foreseen. The effectiveness of other measures like prohibition of mass gatherings or closure of institutions is often assessed in the light of historical events. However, they have to be considered within today's ethical and societal context, taking into account, in particular, the increased number of people who are immunocompromised. Since our knowledge of how the virus would behave today is limited to extrapolations from historical data and is therefore imperfect, these measures are still under discussion. All relevant groups should be involved in exercises to assure the effective operation of the plan mainly regarding communication and cooperation.
\end{abstract}




\section{Introduction}

After the eradication of smallpox, it was possible to cease the most successful strategy against smallpox, namely vaccination. Apart from rare events like the outbreaks of monkeypox in the Democratic Republic of Congo or in the USA [1,2], there has been no need to think about the management of this disease anymore. However, the threat of smallpox being used as a means of bioterrorism has forced reconsideration of the need for smallpox vaccinations and other measures to manage potential cases or outbreaks of smallpox. In the past few years, many countries have developed preparedness plans for smallpox. In the following chapter we have tried to summarize some of the most important issues for the management of smallpox. A full description of all the necessary parts of the preparedness plans would go beyond the space available here.

\section{Strategy}

The strategy for the management of clinical cases of poxviruses (occurring sporadically or in outbreaks) usually includes the early detection of cases, rapid laboratory diagnosis, an assessment of the risk of further spread and containment measures.

\section{Early detection}

Early detection of a first smallpox case will be crucial for a successful management of any new outbreak. The earlier anti-epidemic countermeasures are initiated, the more likely the epidemic can be controlled or prevented in time and casualties can be limited.

Conventional surveillance systems like epidemiological surveillance of a well-defined set of clinically suspected diseases or laboratory confirmed agents are important to monitor and control the occurrence of infectious diseases. Yet, these systems usually detect outbreaks or unusual epidemic developments only with a certain time delay. Therefore, planning considerations include concepts that identify an attack as early as possible [3]. Among such systems are for example strategies to monitor the number of emergency department visits, over-the-counter medication sales or school absenteeism. Also, environmental monitoring systems like air samplers, which permanently test the air for threat agents to detect a biological agent before it causes symptoms, have been suggested. Since they only cover selected areas and have to be analyzed against a background noise, they do not necessarily guarantee a timely recognition of a biological threat [3]. After 11th September 2001, various models of syndromic surveillance have been established and tested in the United States for different syndromes (e.g., [4]), but they also still need to 
prove their value in detecting a bioterrorist attack in a timely manner. Most likely a deliberate release of smallpox would not be detected unless one or more human cases with clinical symptoms of the disease occurred.

The early clinical detection of a smallpox case requires familiarity with the disease pattern. The number of the actually practicing physicians who have clinical experience with smallpox patients is decreasing, and it is therefore necessary to provide special training on the disease pattern, including differential diagnosis to clinicians and practitioners.

The emergence of highly contagious diseases with high mortality and morbidity rates pose an immediate threat to public health and ask for a real time detection of the onset.

\section{Laboratory diagnosis}

As a separate chapter in this book describes poxvirus diagnostics, we will not go into specific diagnostic techniques. A very important issue is the necessity to confirm any suspicion of smallpox as fast as possible to avoid false alarms with far-reaching consequences. To ensure the safety of staff involved in taking samples and performing the diagnostics, good cooperation and agreed procedures between health authorities, clinicians and laboratory staff are required. Electron microscopy and nucleic acid detection are the fastest methods and can give results within $24 \mathrm{~h}$. For culturing the virus, biosafety level 4 facilities are required.

\section{Risk assessment}

An initial suspected smallpox case triggers various notifications according to the requirements of national and international health legislation and regulations. Furthermore, if a deliberate release of the virus seems possible, ${ }^{1}$ an actual threat to the affected state has to be presumed. In this case, disaster management and law enforcement agencies will assist the responsible health authorities to guarantee a comprehensive management in case of a confirmation and the likely spread of the disease. Epidemiological and criminal investigation should be coordinated.

In addition to the national and international notifications based on given case definitions, certain measures are necessary to allow an initial risk assessment of the epidemic development. These measures should follow the algorithms of epidemiological outbreak investigation, such as the tracing and identification of exposed contacts and the sources of infection. Further decisions have to be taken on the basis of a continuous risk assessment.

1 Something very likely in the case of an eradicated disease. The only alternative reason would be an accidental release of the agent. 


\section{Intervention}

Immediate anti-epidemic measures are of considerable importance. A permanent monitoring of the epidemic is necessary to guarantee that the effectiveness of the measures taken can be accurately evaluated, which in turn can lead to new measures or to a modification of the actual strategy. The following target groups for intervention measures can be distinguished:

1. Measures concerning smallpox patients:

Smallpox patients must be transferred immediately to a hospital with an isolation unit for further treatment. If no adequate infrastructure is available, isolation standards should be followed as well as possible (for requirements for isolation and isolation facilities see Tab. 1).

2. Measures concerning contacts of infected persons:

Most important is the vaccination of the contact persons as soon as possible within the first 4 days after exposure and their isolation and observation either at home or in hospital. Contraindications, e.g., history of severe eczema or immunodeficiency have to be weighed against the risk of disease. The treatment of complications resulting from vaccination must be also taken into account.

3. Measures concerning the population:

Even after a deliberate release, it is rather unlikely that a major epidemic or pandemic will occur if the appropriate countermeasures are taken in time. In the event of a smallpox outbreak the population can be protected by the prompt implementation of a vaccination campaign adapted to the epidemic realities. Due to the historical experience, a second eradication of the smallpox disease is possible on the basis of the known eradication measures. The bigger challenge will be the identification and elimination of the sources of the intentional release.

\section{Further public measures}

Furthermore, the spread of a smallpox epidemic can be counteracted by limiting access to public facilities and events and by restricting freedom of movement.

\section{Risk communication}

In addition, recommending appropriate protective measures and risk avoidance behavior to the population will be helpful. It is most important that all the measures taken are communicated to the public according to best practice of a consistent risk communication. 
Table 1. Anti-epidemic measures

\begin{tabular}{|c|c|c|c|}
\hline Measure & How & Who & Where \\
\hline Segregation & $\begin{array}{l}\text { Unspecified measure } \\
\text { aiming at a locally } \\
\text { and timely defined } \\
\text { segregation of the } \\
\text { target groups from } \\
\text { each other and from } \\
\text { susceptible and non- } \\
\text { infected person }\end{array}$ & $\begin{array}{l}\text { Persons who are ill, } \\
\text { suspected of being ill, } \\
\text { suspected of being } \\
\text { infected }\end{array}$ & $\begin{array}{l}\text { Usually in hospitals } \\
\text { or specially equipped } \\
\text { accommodations under } \\
\text { permanent supervision }\end{array}$ \\
\hline $\begin{array}{l}\text { Segregation at } \\
\text { home }\end{array}$ & $\begin{array}{l}\text { Measure ordered by } \\
\text { public health authori- } \\
\text { ties, not to leave the } \\
\text { home, home contacts } \\
\text { are to be reduced to } \\
\text { the absolute necessary } \\
\text { level, or under protec- } \\
\text { tive precautions }\end{array}$ & $\begin{array}{l}\text { Persons who are ill, } \\
\text { suspected of being ill } \\
\text { or being infected } \\
\text { Suspected infection } \\
\text { risk is low or the dis- } \\
\text { ease is not very dan- } \\
\text { gerous }\end{array}$ & Home \\
\hline Supervision & $\begin{array}{l}\text { Regular presentation } \\
\text { at the public health } \\
\text { service or control by } \\
\text { phone }\end{array}$ & $\begin{array}{l}\text { Persons suspected } \\
\text { of being ill or being } \\
\text { infected without symp- } \\
\text { toms } \\
\text { Suspected infection } \\
\text { risk is low or the dis- } \\
\text { ease is not very dan- } \\
\text { gerous }\end{array}$ & \\
\hline Quarantine & Segregation & $\begin{array}{l}\text { Persons suspected of } \\
\text { being infected with a } \\
\text { dangerous disease who } \\
\text { need no treatment } \\
\text { But: no ill persons or } \\
\text { persons being sus- } \\
\text { pected of being ill }\end{array}$ & $\begin{array}{l}\text { At home with special } \\
\text { obligations or in spe- } \\
\text { cial quarantine facili- } \\
\text { ties under permanent } \\
\text { supervision }\end{array}$ \\
\hline Isolation & In-patient treatment & $\begin{array}{l}\text { Ill persons or persons } \\
\text { suspected of being ill } \\
\text { with highly contagious } \\
\text { or very dangerous } \\
\text { infection }\end{array}$ & Special isolation units \\
\hline
\end{tabular}

The general public has to be given consistent information adapted to target groups and the situation via the available media. Information of general relevance can be broadcast nationwide by television, for example, whereas information of regional or local relevance can be transmitted via other media (radio, local newspapers, cars with loudspeakers, leaflets, etc.). The information to be disseminated will include recommendations for protective measures as well as the announcement of restrictions on entry to events and facilities. The protection of the non-infected population will necessitate quarantine measures for suspect cases. 
As viruses do not recognize national borders, international cooperation is also of decisive importance. This may include technical and personnel support as well as the exchange and coordination of information but also coordinated action.

\section{International Health Regulations}

In the revised International Health Regulations adopted by the World Health Assembly in 2005, smallpox is one of the four diseases (the other three are poliomyelitis due to wild-type poliovirus; human influenza caused by a new subtype; severe acute respiratory syndrome, SARS) for which just a single case case is considered unusual or unexpected with potentially serious public health impact, and thus must be notified (http://www.who.int/csr/ ihr/WHA58_3-en.pdf, accessed 6th May 2006). WHO Member States have 5 years to implement the necessary systems for surveillance and response including national focal points, which have to be accessible at all times for communication with the WHO focal points.

\section{Vaccination strategy}

The choice of an adequate vaccination strategy for the case of a re-emergence of smallpox in a country very much depends on the epidemic scenario one has in mind and the general availability and quality of a vaccine. At the same time, logistic aspects of the vaccination strategies have to be considered in preparedness planning, i.e., the facility and personnel resources necessary for the implementation of mass vaccinations have to be determined and identified.

With the exception of the very unlikely situations of an accidental release or a natural re-emergence [caused, for example, by mutants of orthopoxviruses (camel- or monkeypox)], the only realistic scenario for a re-emergence of smallpox is a deliberate release of the agent, which does not necessarily have to follow historic patterns of epidemic spread. Simultaneous and multilocal outbreaks are possible and have to be included as possible scenarios for a comprehensive preparedness planning. Predictive modeling of the epidemic spread has to rely entirely on historic data and is of limited value.

The availability and quality of a vaccine has the most significant influence on the strategy, as there is no evidence of an effective therapy with antiviral drugs against a smallpox infection in humans. The chosen strategy will be determined by the particular epidemiological situation and consideration of the threat of further releases and the risk of secondary infections compared with the well-known adverse effects of the currently available 
vaccines. Unlike during a natural outbreak, the threat of additional intentional releases has to be considered for a vaccination policy.

Various models have been developed to assist in identifying the best use of the available vaccines (e.g., [5-8]), as well as other control measures like case isolation and contact tracing or combinations thereof $[9,10]$. Since all these models have different assumptions for important parameters (like $\mathrm{R}_{0}$ ), the conclusions also vary.

Following historical data from the last natural, in this case imported, smallpox cases in Europe in the decades before and during the eradication, the first step will be - after the immediate isolation measures have been initiated - the vaccination of contacts and simultaneous ring vaccinations.

There are efforts to predict the best anti-epidemic measures on the base of mathematic modeling [7, 9, 11-15]. Such models are fitted in such a way that they can reproduce historical outbreaks very well and try to predict the effects of different anti-epidemic measures on the basis of historical data. The quality and predictive value are limited and depend very much on the inclusion of a sufficient number of necessary and correct parameters. A slight change in a parameter can lead to exaggerated effects that do not follow the common sense experience. A lot of the decisive factors can only be roughly estimated, like transmission rate, population immunity or the effectiveness of a post-exposure vaccination.

Furthermore, as the re-emergence of smallpox is most likely to result from a deliberate release and multiple geographically unlinked outbreaks may be possible, this historically based vaccination strategy might seem idealistic. Public and political pressure and security considerations may quickly lead to the ultimate step, the mandatory vaccination of the entire population. Nevertheless, this should be done after a careful risk-benefit-calculation considering the serious adverse effects of the available vaccines.

\section{Vaccination priorities: First responders, other priority groups}

No matter which strategy is chosen the availability of vaccine is a key issue. Most industrialized countries have acquired a certain stockpile of first or second generation vaccine. The sizes of the stockpiles vary from country to country. Some countries have sufficient stockpiles to cover the whole population, some do not. Therefore, priority population groups have to be identified for vaccination - in accordance with epidemiological, political, ethical and societal necessities and based on a public consensus.

As long as there are no smallpox cases worldwide, obligatory prophylactic vaccinations especially of entire populations are not necessary. The re-emergence of smallpox has a limited likelihood, whereas the certainty of serious adverse effects due to vaccination is a proven fact. Nevertheless, it can be necessary if there is an increased likelihood of occupational expo- 
sure. ${ }^{2}$ Prophylactic vaccination may seem useful for the staff of special isolation units, which are most likely to treat the first smallpox cases or of those laboratories designated for confirmatory diagnostics. In this phase also members of infectious disease task forces (interdisciplinary teams on any administrative level for the initial risk assessment and subsequent investigations) may be offered vaccination on a voluntary basis.

As soon as a first smallpox case is confirmed worldwide, and a real threat and exposure seem more likely, the offer of voluntary vaccination to all professional groups who are required to keep the necessary public services running during a smallpox epidemic has to be considered. These groups include mainly medical staff, fire brigades and disaster relief organizations, Red Cross etc., but also people working in critical infrastructures (power and water supply, public transportation and communication) or for public security and order or on the administration or political level, i.e. those population groups who are relevant for the maintenance of public life.

Once a smallpox case is confirmed, vaccination strategies should focus on the necessities of an anti-epidemic management. First of all the population being affected or at risk must be vaccinated. If the epidemic spread cannot be controlled, mandatory mass vaccinations will be necessary.

\section{Isolation, quarantine}

Smallpox can be spread by droplets and by direct or indirect contact with the pustules on the skin. This assumes that all primary contact persons of a confirmed smallpox case (see Tab. 2) may be infected and must be identified as soon as possible. The risk of infection for persons with an extended contact time or a close contact distance is much higher than for persons with a short contact time.

According to historical data, the highest risk of infection exists for household members or hospital contacts. The European outbreaks between 1950 and 1971 showed that $55 \%$ of the infected persons contracted smallpox at a hospital, $20 \%$ in the family, $14 \%$ at their working place or school and $3 \%$ of the infected persons were working in a laundry, while $8 \%$ were unidentified contacts. None of the 945 smallpox cases in Europe since the Second World War contracted it on an airplane, a train or a bus [16].

Yet, under special conditions, an airborne transmission may be possible. In a hospital in Meschede, Germany, patients and nurses from the two floors above the floor where a smallpox patient was treated were infected by air circulation $[17,18]$. Based on publications on smallpox transmissions, Table 2 describes the risks of infection.

2 e.g. this may be the case for those who work in the field of vaccine development with infectious vaccinia virus or for veterinarians or keepers in zoos who have a higher risk of exposure to other poxviruses. 
Table 2. Categories of the risk of being infected by a contact with a smallpox patient (National German smallpox plan, 2003, www.rki.de/Infektionskrankheiten A-Z, Pocken)

High risk

- Persons who are living in the same household with the patient and persons with a similar risk of infection (members of the family and household contacts, etc.)

- Persons who have had „face-to-face-contact” with a sick person, which includes all persons, who have been so close to the patient that they could be infected by droplets, or who have touched the efflorescence of the skin [e.g., friends or neighbors who have taken care of the patient, physicians who have been consulted before the hospital, hospital staff (medical doctors, nurses, cleaning staff), persons in a public traffic system with direct contact, i.e., less than ca. $2 \mathrm{~m}$ to the infectious case of smallpox, etc.]

- Persons who have been longer in the same (confined) room with a patient (e.g., work colleagues, transport staff of the ambulance, etc.)

- Persons who have direct contact with the dead body of a smallpox patient (e.g., undertaker, pathologist, priest, etc.)

- Persons who have worked with infectious samples of a smallpox patient without appropriate protection

- Persons who have touched scabs of a smallpox patients without appropriate protection

- Persons who have had direct, non-protected contact with the personal clothes, bed linen or other personal belongings, materials that a smallpox patient wore or used after the onset of fever

Medium risk

- Persons who are in the same building as a smallpox case, if this building has a ventilation system, air conditioning or comparable installation systems that circulate the air between different rooms in the building

- Persons who have traveled in the same compartment of a public transportation system or airplane with a ventilation system, air conditioning or comparable installation systems to circulate the air

Low risk

- Persons with a short and/or not close contact to an infectious smallpox case (e.g., a short stay in the same room, or a longer stay in the same building without ventilation system, air conditioning or comparable installation systems to circulate the air; sharing the same public transportation system without ventilation system, air conditioning or comparable installation to circulate the air; distance to the index case $>2 \mathrm{~m}$ )

- Medical staff, if they have used appropriate personal protection equipment

It might be impossible to control an outbreak of smallpox using only vaccination, therefore isolation of cases and monitoring of the contacts may be necessary in addition $[9,19]$. Quarantine in an isolation ward for all persons who were exposed seems to be the safest way, but it has some limitations, like the quantity of qualified isolation wards, the supply of the population with food, drinking water etc. and the cooperation of the population. Therefore, it will be helpful to adjust the anti-epidemic measures to the likelihood of developing the disease (Tab. 1) [20].

The isolation concept should be adapted to the epidemic situation, the requirements on effective isolation and the expected number of contact persons. The personnel in all hospitals/facilities must be vaccinated and trained, personal protective equipment (including gloves, masks, goggles, gowns) and means to follow the hygiene measures must be available. If pri- 
mary contacts develop fever and other typical symptoms of smallpox, their transfer to a hospital with isolation ward is immediately necessary.

For contact persons with a low risk of infection and a timely, successful vaccination, segregation at home seems to be appropriate as long as they have not developed fever, all household contacts have been vaccinated and the local health authority has the capacity to observe them daily.

Nevertheless, it must be kept in mind that a vaccination, even when administered in time, does not yield $100 \%$ protection. According to historical data, the risk of infection for vaccinated household contacts of a smallpox patient in the past was $3.7 \%$ [21], in comparison to $65 \%$ of unvaccinated household contacts. These data did not give any information about when the contact persons had had their last vaccination.

Vaccination should also be offered to secondary contact persons. They must be registered because they will become primary contacts themselves if the originally primary contact develops the disease.

\section{Other restrictions}

Since transmission of smallpox is favored by close distance between persons, so-called "social distancing" measures are considered as further intervention measures to stop the spread. Whereas the isolation of cases or segregation of exposed persons (contacts) is not under debate, the effectiveness of other measures like prohibition of mass gatherings, closure of institutions or even curfews are often assessed in the light of historical events. However, they should be considered within today's ethical and societal context, taking into account differences in the society, in travel behavior, and the increased recognition of contraindications to vaccination [10]. Also, the number of people who are immunocompromised (due to HIV, chemotherapy, transplantations etc.) has increased [10]. These measures are still under discussion, since we have limited knowledge of how the virus would behave today.

\section{Preparation of medical countermeasures}

\section{Vaccination}

According to the vaccination strategy described above, the majority of vaccinations would be carried out in the case of the real event. Therefore, elaborate preparations have to be implemented in the pre-event phase. Smallpox vaccine and bifurcated needles have to be procured and stockpiled. Some governments have a national stockpile of smallpox vaccines, but not all of them have a stockpile covering the need of their entire population. Therefore, multi-lateral support in the case of an event has to be assured in time. Within the European Union, a Task Force on Bioterrorism was set 
up in May 2002 with the main objective of implementing the health security program [22]. The World Health Organization (WHO) has to convince some states to contribute to an international stockpile at WHO level.

For national stockpiles, the logistics for storage, transport and distribution have to be determined in advance as well. To allow immediate mass vaccinations, the required infrastructure, such as facilities or personnel, has to be identified and the latter informed and trained in time. The entire process should be tested and practiced in simulation exercises.

When choosing vaccination facilities important aspects have to be considered to enable the vaccination of a large number of people in a very short time, such as:

- Number and size of vaccination facilities according to population density

- Transport connections

- Easy access, also for handicapped people

- Water and energy supply

- Toilets

- Possibility of separate treatment of suspected cases

- Availability of rooms for personnel, first aid, treatment

- Phone

- Furniture

Material for documentation of the vaccinations and checking of contraindications (questionnaires, vaccination list/card) as well as information for the public has to be produced in advance and distributed to the authorities. They take care of the implementation of preparedness measures on the regional and local level. Other tasks have to be achieved or initiated in the pre-event phase as well: vaccination of the vaccinators, training of the necessary staff and provision of the material needed at the vaccination facilities.

\section{Research on new vaccines}

A survey of over 14 million vaccinations in the USA in 1968 showed that per million vaccinations there were 75 serious adverse effects, including 1 death [23]. Some of the known adverse effects that may arise from smallpox vaccination are post-vaccination encephalitis, progressive vaccinia, eczema vaccinatum or generalized vaccinia. Therefore, the production of modern and more compliant vaccines is under consideration.

A way to minimize the adverse events of smallpox vaccination might be the use of modified vaccinia virus Ankara (MVA), which was developed in the 1970s by more than 500 passages in chicken embryo fibroblasts [24]. However, smallpox had been eradicated before the efficiency of the protective effect of MVA could be tested. Experiments with animals indi- 
cate that there may be fewer complications after vaccination with MVA [25-27], and show also that MVA provokes a high antibody titer and a high concentration of IFN- $\gamma$-positive cells. Some data show that MVA-vaccinated animals are protected against smallpox infection [26,28], but other results allow the interpretation that a MVA-vaccination alone can not guarantee a full protection against infection [25]. MVA might be a good candidate for a pre-immunization [25] or for persons with strong contraindications [26, 29]. Other replication-deficient VACV strains have also been developed for immunization [14,30-32]. Some MVA strains currently under development require a higher virus titer as they do not replicate in the human body.

VACV strains have the potential to inducing post vaccination encephalitis. Derived from historical data with 1-2 cases per million, the vaccination of the entire population of a country like Germany would lead to 80-160 cases of severest adverse effects.

Finally, a lot of research is being performed to develop new vaccines. Experiments on a DNA basis are very promising, even if these vaccines do not fully protect from infection yet $[33,34]$. All the vaccines under development are still in the pre-clinical state.

\section{Vaccination: Legal issues}

Usually, vaccination strategies are chosen on the basis of scientific evidence and national health legislation. For the special case of smallpox, the only vaccine which has proven its efficiency decades ago is known to produce serious side effects. Therefore, legal regulations for the financial compensation of vaccination damages have to be agreed upon and guaranteed before the implementation of vaccinations, no matter if they are being recommended for occupational safety reasons in the pre-event phase or as antiepidemic measure in the case of an event.

\section{Training, exercises}

More than 20 years after the eradication of smallpox only very few health professionals have practical experience with the management of this disease. Therefore, all relevant professions involved in the management of a smallpox outbreak or epidemic have to be trained on the disease pattern and its specific consequences on their professional tasks.

Training must include the professional implementation of sampling techniques as well as safe transport, which have to be arranged in advance to avoid any unnecessary delay or hazard from improper handling or packaging. The laboratories selected for smallpox diagnostics have to guarantee that this can be done both rapidly and with assured quality. These labora- 
tories have to immediately report a suspected or confirmed ${ }^{3}$ laboratory diagnosis to the appropriate authorities.

Public health officers, clinicians and practitioners for example have to update their knowledge on the clinical picture to guarantee an early recognition of the disease and also get familiar with the treatment and therapy of smallpox cases. Laboratory personnel have to be trained in the diagnostics of smallpox on the basis of the Standard Operating Procedures. The validity of the diagnosis is improved by regular participation in a quality assurance system.

In general, if preparedness plans exist, they have to be evaluated among all the relevant groups by exercises to assure the effective operation of the plan mainly in the field of communication and cooperation. Public health services might test the implementation of mass vaccinations or the reporting systems for a smallpox alert; clinicians might check the clinics' preparedness plans for cases of highly contagious diseases, ambulance services might train for the transport of highly contagious patients and all together they might check the interaction between the relevant actors aiming at a harmonization of the preparedness planning.

\section{References}

1 Hutin YJF, Williams RJ, Malfait P, Pebody R, Loparev VN, Ropp SL, Rodriguez M, Knight JC, Tshioko FK, Khan AS et al (2001) Outbreak of human monkeypox, Democratic Republic of Congo, 1996-1997. Emerg Infect Dis 7: 434-438

2 CDC (2003) Update: Multistate outbreak of monkeypox - Illinois, Indiana, Kansas, Missouri, Ohio, and Wisconsin, 2003. MMWR 52: 561-564

3 Rotz LS, Hughes JM (2004) Advances in detecting and responding to threats from bioterrorism and emerging infectious diseases. Nat Med 10: S130-136

4 Heffernan R, Mostashari F, Das D, Karpati A, Kulldorff M, Weiss D (2004) Syndromic surveillance in public health practice, New York City. Emerg Infect Dis 10: 858-864

5 Kretzschmar M, van den Hof S, Wallinga J, van Wijngaarden J (2004) Ring vaccination and smallpox control. Emerg Infect Dis 10: 832-841

6 Legrand J, Viboud C, Boelle PY, Valleron AJ, Falhault A (2003) Modelling responses to a smallpox epidemic taking into account uncertainty. Epidemiol Infect 132: 19-25

7 Bozzette SA, Boer R, Bhatnagar V, Brower JL, Keeler EB, Morton SC, Stoto MA (2003) A model for a smallpox-vaccination policy. $N$ Engl J Med 348: 416-425

8 Massoudi MS, Barker L, Schwartz B (2003) Effectiveness of a postexposure vaccination for the prevention of smallpox: results of a Delphi analysis. J Infect Dis 188: 973-976

3 A first smallpox case or first smallpox cases would need "official" confirmation in one of the two laboratories designated by WHO (CDC and VECTOR). 
9 Eichner M (2003) Case isolation and contact tracing can prevent the spread of smallpox. Am J Epidemiol 158: 118-128

10 Kerrod E, Geddes AM, Regan M, Leach S (2005) Surveillance and control measures during smallpox outbreaks. Emerg Infect Dis 11:291-297

11 Epstein JM, Cummings DAT, Chakravarty S, Singa RM, Burke DS (2005) Towards a containment strategy for smallpox bioterror: an individual-based computational approach. [cited 2005 Nov 21]; available from: URL: http:// homepage.univie.ac.at/Franz.Vesely/ABC_Korneuburg/pdf/bio_terror_ epstein.pdf

12 Halloran ME, Longini J, Nizam A, Yang Y (2002) Containing bioterrorist smallpox. Science 298: 1428-1431

13 Gani R, Leach S (2001) Transmission potential of smallpox in contemporary populations. Nature 414: 748-751

14 Edghill-Smith Y, Venzon D, Karpova T, McNally J, Nacsa J,Tsai WP, Tryniszewska E, Moniuszko M, Manischewitz J, King LR et al (2003) Modeling a safer smallpox vaccination regimen, for human immunodeficiency virus type 1-infected patients. In: Immunocompromised Macaques. J Infect Dis 188: 1181-1191

15 Meltzer M, I, Damon I, LeDuc JW, Millar D (2001) Modeling potential responses to smallpox as a bioterrorist weapon. Emerg Infect Dis7: 959-969

16 Mack TM (1972) Smallpox in Europe, 1950-1971. J Infect Dis 125: 161-169.

17 Mack T (2003) A different view of smallpox and vaccination. N Engl J Med 348: 460-463

18 Wehrle PF, Posch J, Richter KH, Henderson DA (1970) An airborne outbreak of smallpox in a German hospital and its significance with respect to other recent outbreaks in Europe. Bull World Health Organ 43: 669-679

19 Gelfand HM, Posch J (1971) The recent outbreak of smallpox in Meschede, West Germany. Am J Epidemiol 93: 234-237

20 Fock R, Finke EJ, Fleischer K, Gottschalk R, Graf P, Grünewald T, Koch U, Michels H, Peters M, Wirtz A et al (2005) Begriffsbestimmungen seuchenhygienisch relevanter Maßnahmen und Bezeichnungen. In: Biologische Gefahren. Beiträge zum Bevölkerungsschutz, 2nd edn. Bundesamt für Bevölkerungsschutz und Katastrophenhilfe, Bonn, 211-230

21 Fenner F, Henderson DA, Arita I, Jezek Z, Ladnyi ID (1988) Smallpox and its eradication. WHO, Geneva

22 Tegnell A, Bossi P, Baka A, van Loock F, Jendriks J, Wallyn S, Gouvras G (2003) The European Commission's Task Force on Bioterrorism. Emerg Infect Dis 10: $1330-1332$

23 Lane JM, Ruben FL, Neff JM, Millar JD (1969) Complications of smallpox vaccination, 1968/National Surveillance in the United States. N Engl J Med 281: 1201-1208

24 Mayr A, Stickl H, Müller HK, Danner K, Singer H (1978) Der Pockenimpfstamm MVA: Marker, genetische Struktur, Erfahrungen mit der parenteralen Schutzimpfung und Verhalten im abwehrgeschwächten Organismus [The Smallpox Vaccinnation Strain MVA: Marker, Genetic Structure, Experience Gained with the Parenteral Vaccination and Effect in Immunocomprimised Organism]. Zentralbl Bakteriol Hyg 167: 375-390

25 Earl PL, Americo JL, Wyatt LS, Eller LA, Whitbeck JC, Cohen GH, Eisenberg 
RJ, Hartmann CJ, Jackson DL, Kulesh DA et al (2004) Immunogenicity of a highly attenuated MVA smallpox vaccine and protection against monkeypox. Nature 428: 182-185

26 Wyatt LS, Earl PL, Eller LA, Moss B (2004) Highly attenuated smallpox vaccine protects mice with and without immune deficiencies against pathogenic vaccinia virus challenge. Proc Natl Acad Sci USA 101: 4590-4595

27 Stittelaar KJ, van Amerongen G, Kondova I, Kuiken T, van Lavieren RF, Pistoor FH, Niesters HG, van Doornum G, van der Zeijst BA, Mateo L et al (2005) Modified vaccinia virus Ankara protects macaques against respiratory challenge with monkeypox virus. J Virol 79: 7845-7851

28 Belyakov IM, Earl P, Dzutsev A, Kuznetsov VA, Lemon M, Wyatt LS, Snyder JT, Ahlers JD, Franchini G, Moss B, Berzofsky JA (2003) Shared modes of protection against poxvirus infection by attenuated and conventional smallpox vaccine viruses. Proc Natl Acad Sci USA 100: 9458-9463

29 McCurdy LH, Larkin BD, Martin JE, Graham BS (2004) Modified Vaccinia Ankara; potential as an alternative smallpox vaccine. Clin Infect Dis 38: 1749-1753

30 Ober BT, Bruhl P, Schmidt M, Wieser V, Gritschenberger W, Coulibaly S, Savidis-Dacho H, Gerencer M, Falkner FG (2002) Immunogenicity and safety of defective vaccinia virus lister: comparison with modified vaccinia virus Ankara. J Virol 76: 7713-7723

31 Legrand FA, Verardi PH, Jones LA, Chan KS, Peng Y, Yilma TD (2004) Induction of potent humoral and cell-mediated immune responses by attenuated vaccinia virus vectors with deleted serpin genes. $J$ Virol 78: 2770-2779

32 Kidokoro M, Tashiro M, Shida H (2005) Genetically stable and fully effective smallpox vaccine strain constructed from highly attenuated vaccinia LC16m8. Proc Natl Acad Sci USA 102: 4152-4157

33 Enserink M (2004) Smallpox vaccines: looking beyond the next generation. Science 304: 809

34 Hooper JW, Thompson E, Wilhelmsen C, Zimmerman M, Ichou MA, Steffen SE, Schmaljohn CS, Schmaljohn AL, Jahrling PB (2004) Smallpox DNA vaccine protects nonhuman primates against lethal monkeypox. J Virol 78: 4433-4443 